\title{
Research Regarding Prelevation and Preparation of Porcine Small Intestinal Submucosa for Corneal Reconstruction in Dogs and Cats
}

\author{
Ioana Alina DÎRLEA*, Aurel MUSTE, Forin BETEG, Loredana HODIS, Teodor STROE, \\ Reka VARGA
}

University of Agricultural Sciences and Veterinary Medicine, Cluj-Napoca, Faculty of Veterinary Medicine, 3-5 Mănăștur Street, 400372, Cluj-Napoca, România

* Corresponding author: dirleaioana@yahoo.com

Bulletin UASVM Veterinary Medicine 73(1) / 2016,

Print ISSN 1843-5270; Electronic ISSN 1843-5378

DOI:10.15835/buasvmcn-vm: 10963

\begin{abstract}
Porcine small intestinal submucosa (SIS) is a biomaterial, consisting of collagen, proteoglycan glycosaminoglycan, glycoprotein and growth factors. This study was conducted within the Surgery Department of the Faculty of Veterinary Medicine in Cluj-Napoca, on one healthy pig, four months, in November, 2013. After the pig was humanely euthanized, a segment of proximal jejunum was obtained following a midline abdominal wall incision. All mesenteric tissues, mucosa and serosa tunica were resected from the intestine using a sterile scalpel and moistened gauze in sterile saline. The material was rinsed in sterile saline and stored in a solution containing neomycin sulphate $10 \%$ at 4 degree Celsius. Up to ten days from sampling preserved SIS specimens can be used with success in the surgical procedures of corneal reconstruction in small animals.
\end{abstract}

Keywords: corneal reconstruction, pig, small intestine submucosa

\section{INTRODUCTION}

Severe corneal defects in small animals should be treated surgically for optimum results. There are many techniques for surgical management of this pathology, but all require expensive equipment and specialist skills. In veterinary ophthalmology are successfully used conjunctival pedicle grafts, but that can impair vision when the pathology is located on the axial cornea. The ideal biomaterial for corneal reconstruction should support epithelial migration and adhesion, permeability to solutes and stability to corneal proteases. In the efforts to identify the perfect material for the reconstruction of cornea, numerous non-corneal grafts have been employed with good result: equine pericardium (Barros et al., 1993), equine amniotic membrane (Barros et al., 1998), human amniotic membrane (Kim and Tseng, 1995), equine renal capsule (Andrade et al., 1999), and peritoneum (Garcia et al., 1996).

Porcine small intestinal submucosa (SIS) is a biomaterial used with success in tissue engineering; was investigated for the first time as a vascular graft (Badylak, 1989). The material ranges in thickness from $0.05 \mathrm{~mm}$ to $0.22 \mathrm{~mm}$ (Shi and Ronfard, 2013). SIS is primarly composed of type I collagen fibres, but also contains collagen type III, IV and VI. Glycoproteins like fibronectin and laminin, found in its structure, mediate the cell adhesion to the extracellular matrix (Shi and Ronfard, 2013). The growth factors reported in SIS are fibroblast growth factor (FGF-2), transforming growth factor-beta1(TGH- $\beta 1)$ and vascular 
endothelial factor (VE-GF) (Shi and Ronfard, 2013).

SIS is acellular collagen matrix which acts as a medium for corneal remodelling and reconstruction. Its structure represent an excellent choice for tissue engineering and clinical aplications (Lewin 1999, Featherstone and Sansom 2001).

The purpose of this study was to ilustrate the method of prelevation and conservation of fresh SIS for the use in surgical treatment of severe corneal disorders in what species?

\section{MATERIALS AND METHODS}

This study was conducted within the Surgery Department of the Faculty of Veterinary Medicine Cluj-Napoca, in November 2013. For prelevation of swine small intestinal submucosa was used a healthy donor female pig, $40 \mathrm{~kg}$ body weight. The pig was humanely euthanized using premedication with Azaperone (Stresnil ${ }^{\circledR}$, Vétoquinol: $1-8 \mathrm{mg} / \mathrm{kg}$ BW IM,), Ketamine (Imalgene ${ }^{\circledR}$, Merial 15-20mg/ kg BW, IM,) for analgesia and Embutramide (T.61 ${ }^{\circledR}$, Intervet: 4-6 ml/50 kg BW, IV). Within two hours from the donor pig euthanasia a segment

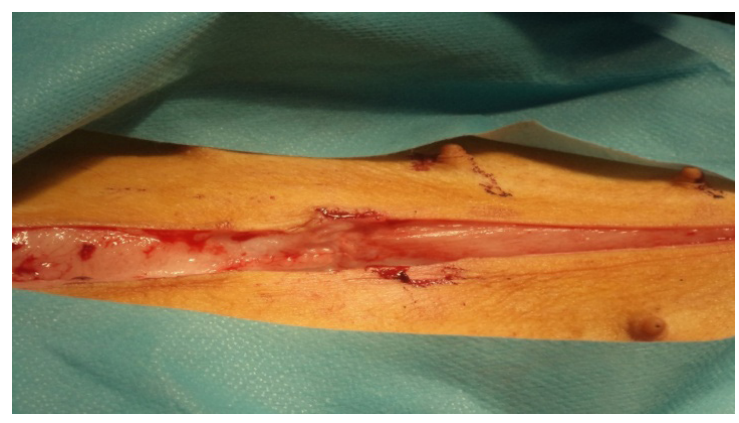

Fig. 1. Middle abdominal wall incision

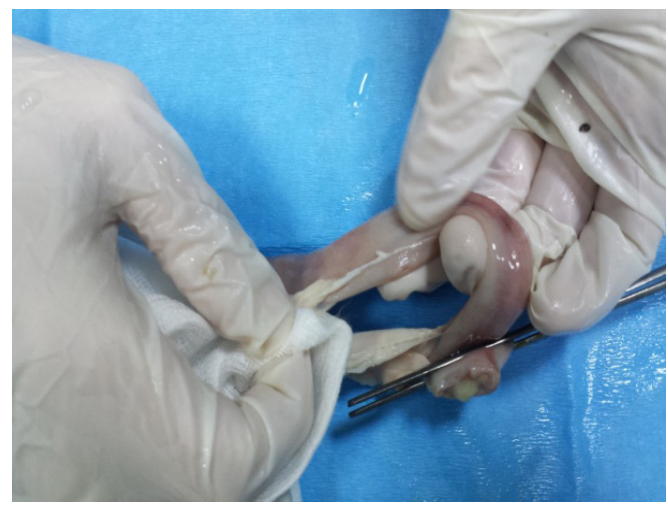

Fig. 3. Removing the mesenteric tissues of the proximal jejunum was obtained following a middle abdominal wall incision (Fig. 1, Fig. 2.)

The proximal jejunum was wrapped in surgical sponges that were initially soaked in sterile saline $(0.9 \% \mathrm{NaCl})$ solution. All mesenteric tissues were removed and the segment of jejunum was everted (Fig.3 and Fig. 4).

The tunica mucosa was removed using a longitudinal wiping motion with a scalpel handle and moistened gauze (Fig. 5). The segment was returned to the original orientation and the tunica serosa and tunica muscularis were removed from the intestine by similar method. The remaining thin, whitish, translucent tube consisted of tunica submucosa (Fig. 6). The SIS was rinsed in sterile saline several times (Fig. 7).

Submucosa was cut with scissors to obtain a single layer of material then rinsed again in sterile saline solution (Fig. 8). Further, we divided the larger segment into 40x40 mm sections (Fig. $9)$. The tunica muscularis mucosal surface is represented by the 'rough surface', and the stratum compactum surface of the tunica mucosa by the 'smooth surface'. Finally, the SIS segments were

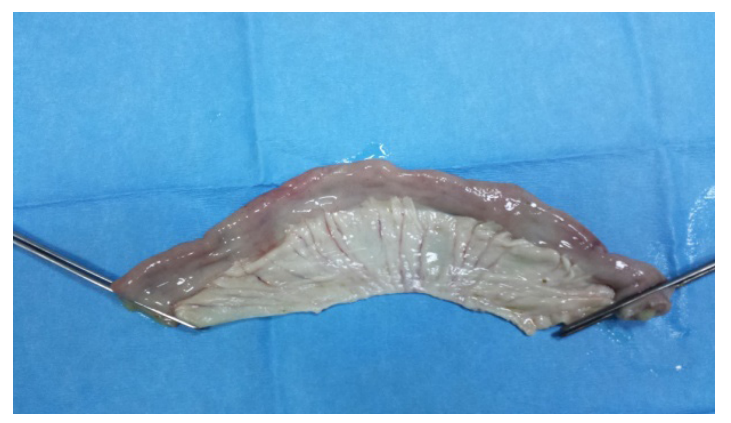

Fig. 2. A segment of proximal jejunum

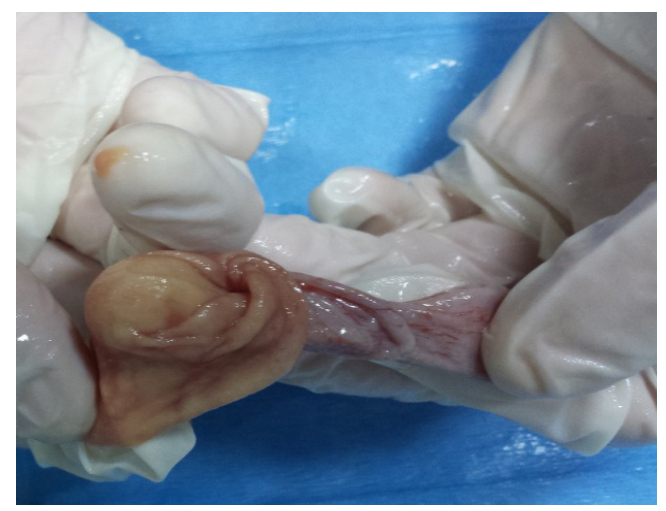

Fig. 4. The intestine was everted 

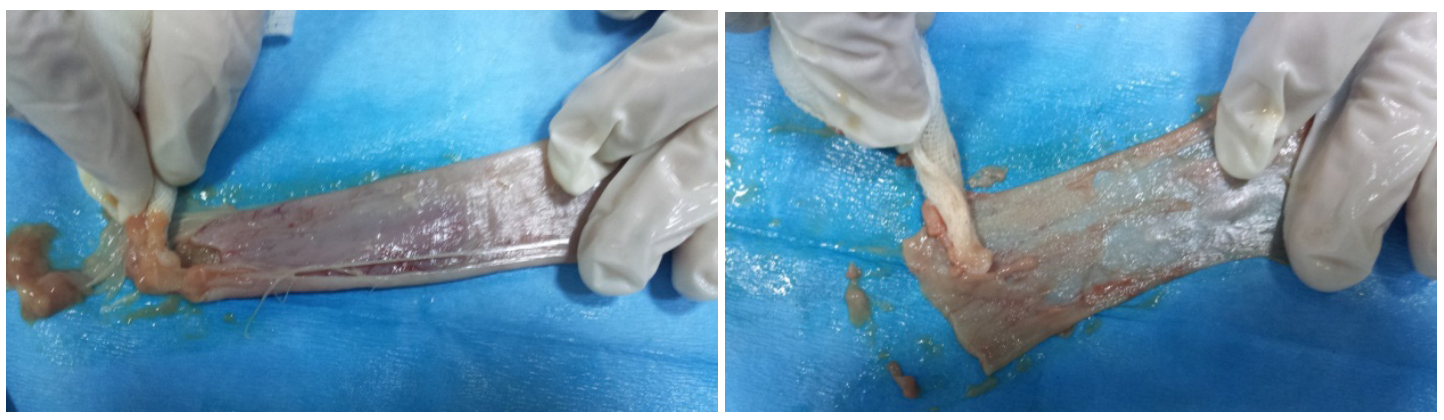

Fig. 5. Removing the tunica mucosa

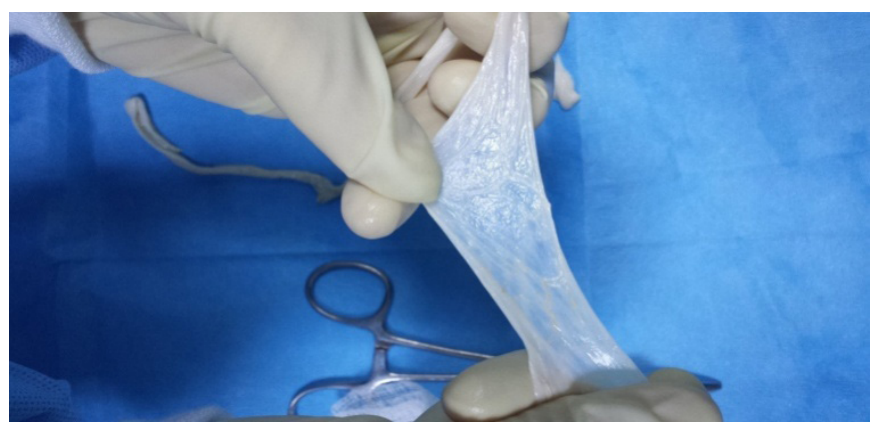

Fig. 6. SIS after removing all others layers
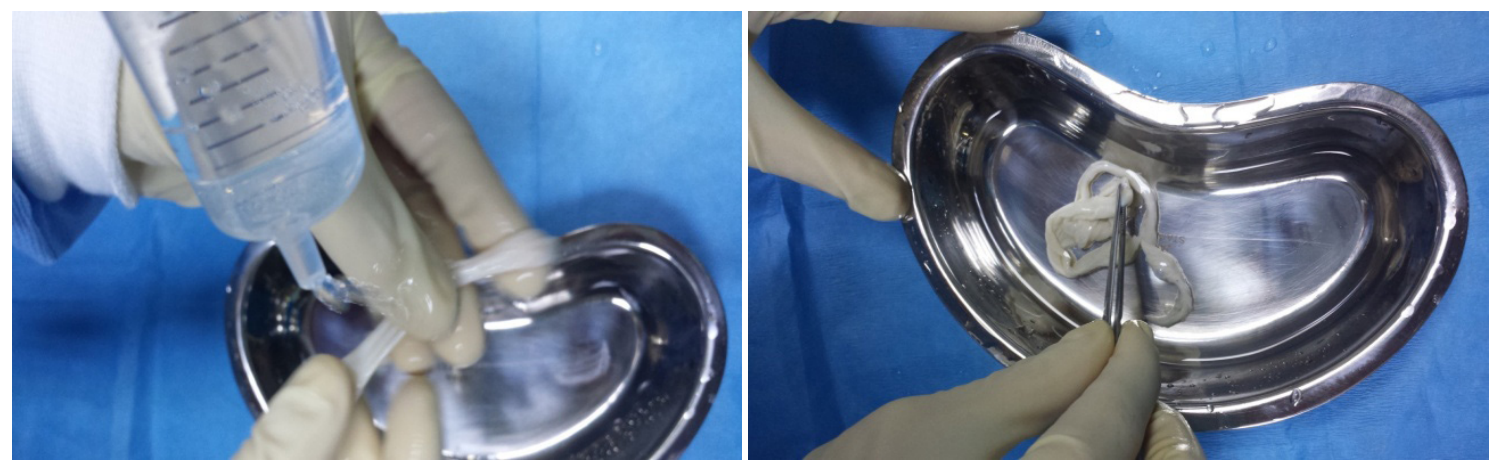

Fig. 7. SIS rinsed in sterile saline

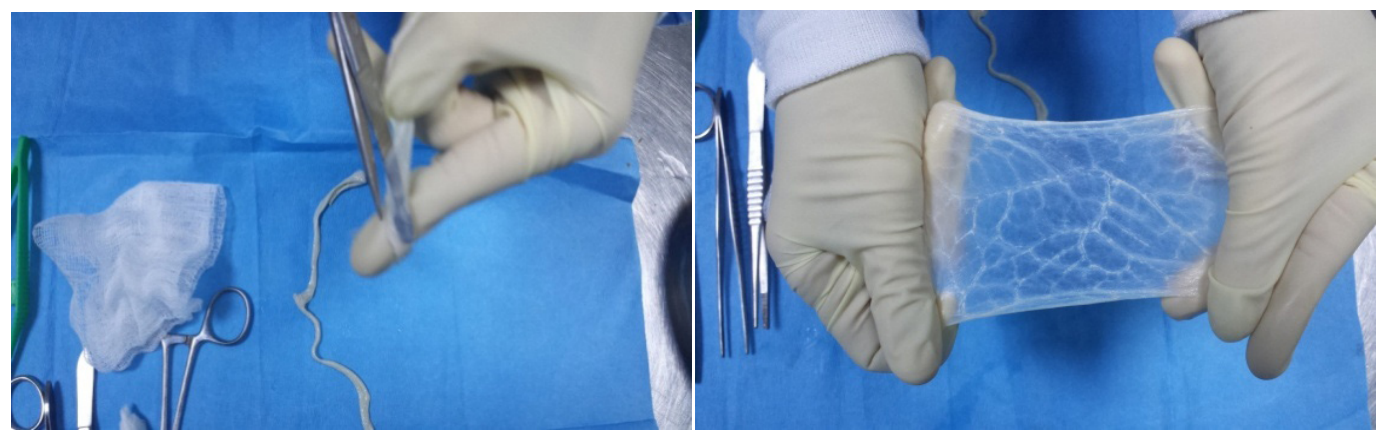

Fig. 8. Longitudinal cut of SIS 
preserved in sterile neomycin sulphate solution, $10 \%$ at $4^{\circ} \mathrm{C}$ until use (Fig. 10).

\section{RESULTS AND DISCUSSION}

Corneal pathology is a common problem in small animal ophthalmology and requires prompt diagnosis and adequate treatment. A number of surgical options can be used, each having both advantages and limitations.

The most commonly surgical techniques are conjunctival grafts. Although these procedures have been shown to be effective, they can also lead to scarring and pigmentation of the recipient cornea (Hakanson and Merideth, 1987) Corneascleral transposition, autologous sliding lamellar keratoplasty, or homologous lamellar corneal transplantation is also useful when there is a risk of perforation, have the advantages to allow for better cosmetic appearance and functional vision than conjunctival grafts, but the use of fresh or preserved homologous lamellar grafts may be limited by the difficulty of harvesting and donor tissue preparation.

SIS biomaterial is capable of inducing host tissue proliferation and replacement when is implanted in corneal sites, through smart remodeling. The biomaterial provides a scaffold for regeneration of the host tissue (Lewin, 1999). Several characteristics of the SIS make it a perfect choice for corneal reconstruction in small animals. The biomaterial is prepared from swine tissue, which is available being a by-product of the meat industry and SIS is minimally processed to provide a sterile biomaterial and cell-free. The absence of highly complicated technological processing means that production costs will be lower. Development of lower cost for corneal reconstruction surgery it's our aim. The facilitated epithelialization with the biomaterial results in a tissue that has minimal scarring is a very important aspect in ophthalmology.

Studies revealed that treatment with neomycin $10 \%$ it was without effect on the remodeling properties of the biomaterial (Badylak et al., 1995). Neomycin sulphate $10 \%$ is highly active against gram-negative, has partial activity against Gram-positive bacteria and it was useful to prevent contamination of SIS until the surgery days, it was not necessary to use cocktails of two or three antibiotics. Submucosa was used with success in up to 10 days from preservation date (Fig. 11) in surgical procedures for corneal

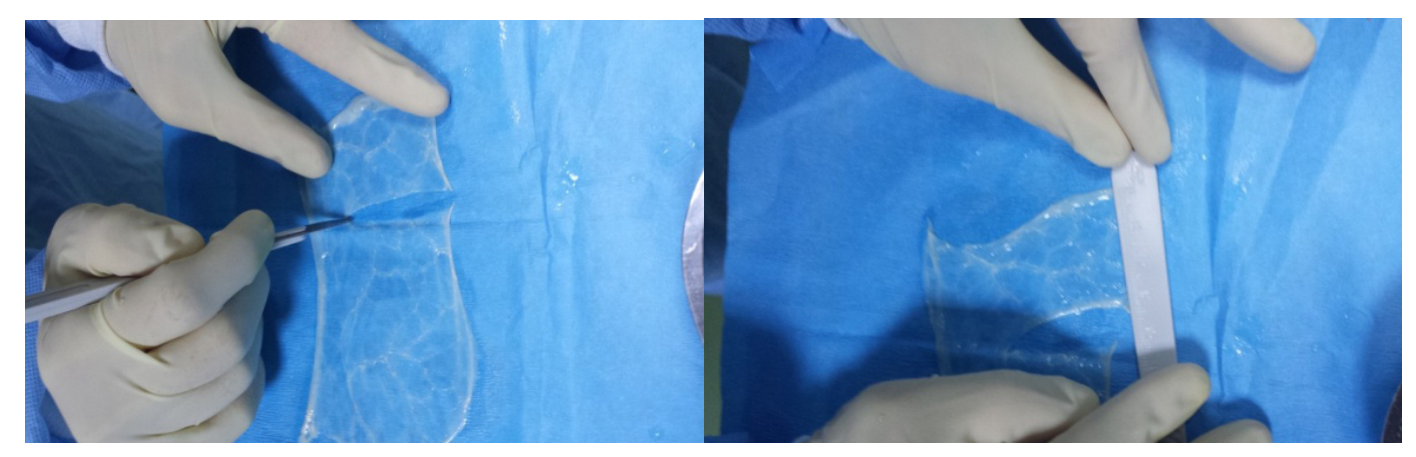

Fig. 9. The SIS divided in 40x40 mm sections

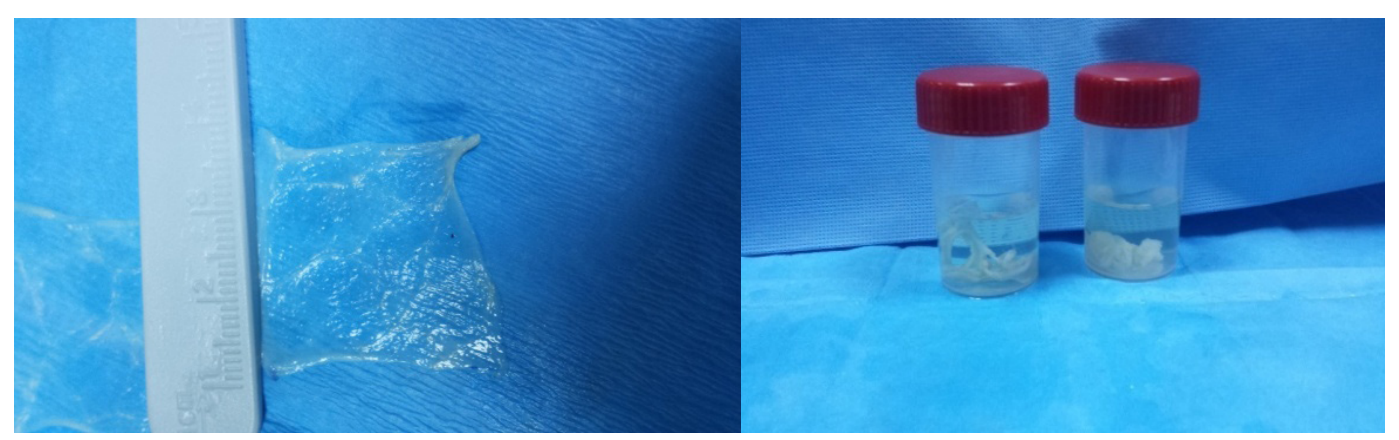

Fig. 10. The final result and storage in neomycin sterile sulphate solution 


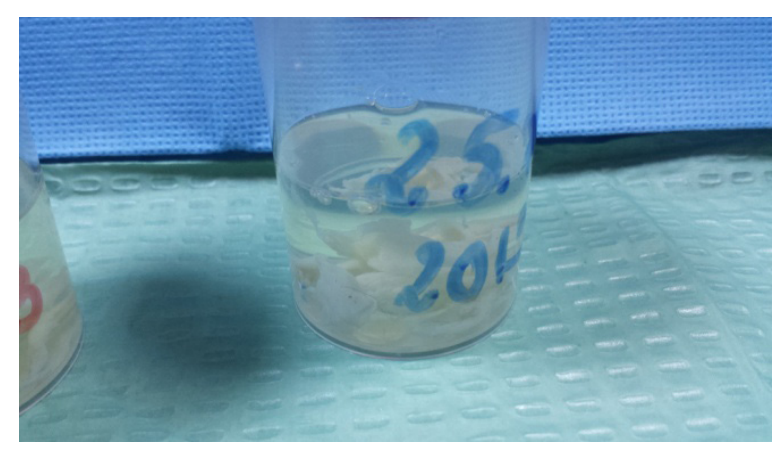

Fig. 11. The SIS after 10 days from sampling

reconstruction in small animals. Lyophilisation of the material is required to preserve and use SIS for at least 1 year.

\section{CONCLUSION}

SIS is translucent and thus offers advantages for corneal surgery. This method of prelevation and preservation of fresh SIS is one of the easiest and inexpensive methods used in corneal reconstruction surgery. Fresh SIS prepared by this method can be used with success in the surgical procedures of corneal reconstruction up to 10 days from sampling.

\section{REFERENCES}

1. Andrade A, LausJ, Figueirido F (1999). The use of preserved equine renal capsule to repair lamellar corneal lesions in normal dogs. Veterinary Ophthalmology 2:79-82.

2. Badylak S, Lantz G, Coffey A, Geddes L. (1989) Small intestinal submucosa as a large diameter vascular graft in the dog. J Surg Res 47(1): 74-80.

3. Badylak SF, Tulleius R, Kokini K (1995). The use of xenogenic small intestinal submucosa as a biomaterial for achille's tendon repair in a dog model. J Biomat Matter Res 29:977-85.

4. Barros P, Safatle A, Godoy C, Souza M, Barros L, Brooks D (2005). Amniotic membrane transplantation for the reconstruction of the ocular surface in three cases. Veterinary Ophthalmology 8:189-192.

5. Barros P, Garcia JA, Laus J, Ferreira A, Salles Gomes T (1998). The use of xenologous amniotic membrane to repair canine corneal perforation created by penetrating keratectomy. Veterinary Ophtalmology 1:119-123.

6. Featherstone HJ, Sansom J (2001). Intestinal submucosal repair in two cases of feline ulcerative keratitis Veterinary Record 146: 136-138.

7. Garcia JA, Barros PSM, Laus JL (1996). Preserved homologous peritoneum graft after lamellar keratectomy in dogs. Brazilian Journal of Veterinary Research and Animal Science 36 (Suppl):290-294.

8. Lewin G (1999). Repair of a full thickness cornescleral defect in a German shepherd dog using porcine small intestinal submucosa. Journal of Small Animl Practice 40:340-342.

9. Hakanson NE ,Merideth RE (1987). Conjunctival pedicle grafting in the treatment of corneal ulcers in the dog and cat. J Am Anim Hosp Assoc 23:641-648.

10. Kim J, Tseng S (1995). Transplantation of preserved human amniotic membrane for surface reconstruction in severely damaged rabbit corneas. Cornea 14:473-84.

11. Shi L, Ronfard V (2013). Biochemical and biomechanical characterization of porcine small intestinal submucosa (SIS): a mini review. Int J Burns Trauma 3(4):173-179. 